\title{
Review
}

\section{Business Models for the Internet of Services: State of the Art and Research Agenda}

\author{
Jacqueline Zonichenn Reis ${ }^{1, * \mathbb{C}}$, Rodrigo Franco Gonçalves ${ }^{1,2}$, Marcia Terra da Silva ${ }^{1}$ and Nikolai Kazantsev ${ }^{3,4}$ \\ 1 Postgraduate Program in Production Engineering, Universidade Paulista, Sao Paulo 04026-002, Brazil; \\ rodrigo.goncalves@docente.unip.br (R.F.G.); marcia.silva@docente.unip.br (M.T.d.S.) \\ 2 Polytechnic School, University of Sao Paulo, Sao Paulo 05508-220, Brazil \\ 3 DIGIT Lab, University of Exeter, Exeter EX4 4QG, UK; n.kazantsev@exeter.ac.uk \\ 4 Graduate School of Business, HSE University, 119049 Moscow, Russia \\ * Correspondence: zonichenn@hotmail.com or jacqueline.reis3@aluno.unip.br
}

check for updates

Citation: Reis, J.Z.; Gonçalves, R.F.; Silva, M.T.d.; Kazantsev, N. Business Models for the Internet of Services: State of the Art and Research Agenda. Future Internet 2022, 14, 74. https:// doi.org/10.3390/fi14030074

Academic Editors: Carlos Filipe Da Silva Portela and Dino Giuli

Received: 30 January 2022

Accepted: 21 February 2022

Published: 25 February 2022

Publisher's Note: MDPI stays neutral with regard to jurisdictional claims in published maps and institutional affiliations.

Copyright: () 2022 by the authors Licensee MDPI, Basel, Switzerland. This article is an open access article distributed under the terms and conditions of the Creative Commons Attribution (CC BY) license (https:// creativecommons.org/licenses/by/ $4.0 /)$.

\begin{abstract}
The relevance of the Internet of Services (IoS) comes from the global reach of the Internet into everyone's home and daily activities and from the move from a manufacturing-based economy to a service-based economy. The IoS is seen as a new ecosystem where service providers and consumers explore their business networks for service provision and consumption. The scientific literature refers to IoS as an important cornerstone for Industry 4.0 and Future Internet; thus, it becomes relevant to study how IoS interacts with business models. Nevertheless, there is a lack of clarity on such an intersection. Moreover, a systematic review of IoS-based business models is still missing. This paper aims to make a systematic review of IoS-based business models and their application fields. We included studies from Scopus and Web of Science databases, we excluded duplicated papers and short conference versions of the later full paper journal publications. Twenty-three different studies are presented, categorized in the sub-areas of IoS, and then by the fields of applications. The main finding highlights the opportunities of IoS applications in different fields, offering directions for future research on this new arena.
\end{abstract}

Keywords: Internet of Services; business model; services; innovation

\section{Introduction}

While the technological advances in the more recent past have opened up a range of new business opportunities [1], both enterprises and software vendors have struggled with the fact that the ICT (Information and Communication Technologies) systems, mostly acquired for more extended periods of time, are exposed to disruptive innovative technologies which have to be rapidly introduced in order for companies to remain competitive in the market [2]. Furthermore, the success of companies in achieving their goals depends on how they integrate the different digital technologies into their business models [3].

New software and services are being developed at an impressive speed and deployed on the Internet, along with virtualized services that connect real-world physical resources. Services from multiple networks converge into a complex ecosystem called the Internet of Services (IoS) [4].

The IoS gains relevance in the scientific literature as an important cornerstone of Future Internet [5], and Industry 4.0, coupled with the Internet of Things (IoT) [1,6]. Through the IoS, the cross-organizational services are offered and used by the value chain participants [7].

A service ecosystems perspective on business models offers rich implications for an enterprise's strategy [8]. Recent research, though, raises problems in regard to "the adaptation of business models to services scenarios, such as the reconfiguration of value chains, the customization and new forms that business models will adopt, and the sharing 
resources in the network of companies operating under flexible supply chains" [9]. The IoS may provide solutions for such challenges; however, the corresponding literature is scarce.

While there is a great focus on IoT, there is a lack of clarity on IoS applications and contributions to the business ecosystem. Research is needed for a business model to adopt an IoS ecosystem perspective, instead of firm-centric models as servitization and digitalization. Moreover, a systematic literature review regarding IoS and its correlation with business models is still missing.

In this sense, the aim of this paper is to highlight the research directions in the field of IoS-based business models. The study presents the results of a systematic literature review correlating the keywords Internet of Services and business model. Twenty-three different studies are presented as well as the problem they address and proposed solution. The review allows identifying the state of the art and the possible gaps addressed by a research agenda.

\section{Theoretical Foundation}

\subsection{Internet of Services}

While humans first delivered services to humans, technological advances over the years allowed computers to deliver services to humans.

The term IoS-based service is used to identify services discovered, ordered, and provided through the Internet [10]. When there is a service request, the requester informs specifications to the provider, that customize the feedback, returning value-added result. Both requester and provider can operate automatically or with humans through a humanmachine interface. Furthermore, automated systems can also invoke the services to access functions provided remotely by business providers [10].

An example of an IoS-based service would be a value-added service package of a system used for monitoring public lighting poles, connected to the city's municipality network. In addition to light intensity measurements on each light pole, this system collects other environmental parameters such as $\mathrm{CO}_{2}$ level, temperature, noise, etc. Then, through the IoS, third-party service providers can use the collected data to optimize or offer new services to people who are connected, such as secure access to homes, predictive maintenance, sustainability applications, etc.

The IoS is seen as an ecosystem that allows services vendors and consumers to collaborate across organizations via the Internet, increasing the popularity of business services in the business markets [11].

Christoph Schroth and Till Janner first coined the term in 2007 [12]. According to them, the IoS is a result from the merge of two other components: Web 2.0 and Service-Oriented Architecture (SOA). The confluence of these two areas reveals the idea of composing and reutilizing services as they were flexible modules.

While SOA and Web services enable service procurement through different channels, their main goal is to provide the technological infrastructure for the IoS, which is a more complex ecosystem.

The main goal of IoS is to present everything as a service on the Internet, such as the software applications, the platform for development and delivery, and the network infrastructure [13]. Nevertheless, developing solutions for the IoS is more elaborate since services are intangible, often inseparable, immersive, bi-polar, hybrid, variable, ostensible concerning ownership, have long-running interactions, and are decoupled [14].

For some authors, IoS is a "future internet that detect, and use contextual information for seamlessly adapt to an unpredicted scenario" [5,15].

Within the IoS, service providers work collaboratively to offer and deliver services. A service-based value network may cover the entire lifecycle, from R\&D to operations, passing through the design, marketing, sales, production, and delivery of a service. All the areas should interactively cooperate to add value to the service. Value is created from the collaboration among the different stakeholders: the company, its customers, intermediaries and suppliers [10]. 


\subsection{Business Model}

A business model is a "conceptual tool containing a set of concepts and relationships to express a business logic. It must consider which relationships allow a description and representation of what value is provided to customers, how this is done, and the financial consequences" [16].

The business model has been employed mainly in trying to address or explain three phenomena: (1) e-business and the use of information technology in organizations; (2) strategic issues, such as value creation, competitive advantage, and firm performance; and (3) innovation and technology management [17].

Although there is a consensus on how important a business model is for the business success, the literature has yet to conceptualize what business models do and how they intend to create new structures for an innovative market [8]. The emerging Business Model Innovation (BMI) literature raises new applications as servitization, open innovation and dynamic capabilities [18]. Nevertheless, "little is known about how a shift toward servicedriven models affects the firm's existing business model and the structure to support the new business model" [19].

Despite the various terminologies and the lack of a uniform taxonomy for building a business model, an approach accepted both in the practice and literature [20-23] is the Business Model Canvas developed by Osterwalder \& Pigneur (2010) [24]. It identifies nine building blocks or components including customer segments, value proposition, channels, customer relationships, revenue streams, key resources, key activities, key partnerships, and cost structure.

The Business Model Canvas representation is understood as interrelated building blocks that address the four meta-components: value proposition, value creation, value delivery and value capture [20].

The analysis of the business model dimensions is crucial for designing a solution considering the key functions of an organization. "The mechanisms for creating, delivering, and capturing value reflect components that are well understood in the BM and BMI literatures-namely, value proposition, target segments, value chain organization, and revenue capture mechanisms" [18].

Instead of explaining business solely through individual activities such as marketing and R\&D, or through mechanisms influencing business outcomes such as value chain or pricing, the research on business models highlights the development of holistic, multidimensional, system-level business model frameworks [17].

There are several types of business models for digital services, which present different payment methods and exploited properties. Among the examples discussed by Øverby and Audestad [25], there is the subscription model in which users pay a fee for using the service, like in the massive online game World of Warcraft. There is the freemium model, when some users receive the service for free while others pay for using the service, e.g., Spotify. There are the multisided digital mediation platforms, such as Airbnb, in which the users pay for the mediation services provided by the platform.

\section{Materials and Methods}

A systematic literature review was carried out to identify the state-of-the-art Internet of Services and the interaction with business models. The systematic review is a means of identifying, evaluating and interpreting all available research relevant to a particular research question or phenomenon of interest [26].

We studied two research questions:

1. What is the state of the art of Internet of Services-based business models?

2. What is their classification based on the application field?

This review followed the PRISMA (http:/ / www.prisma-statement.org/ (accessed 28 January 2022)) guidelines which employs a method for conducting the review, such as Systematic Literature Review. PRISMA is an evidence-based minimum set of items for reporting in systematic reviews and meta-analyses, which focuses on the reporting of 
reviews evaluating the effects of interventions, but can also be used as a basis for reporting systematic reviews with objectives other than evaluating interventions [27]. Figure 1 shows the PRIMA flow diagram for the systematic review.

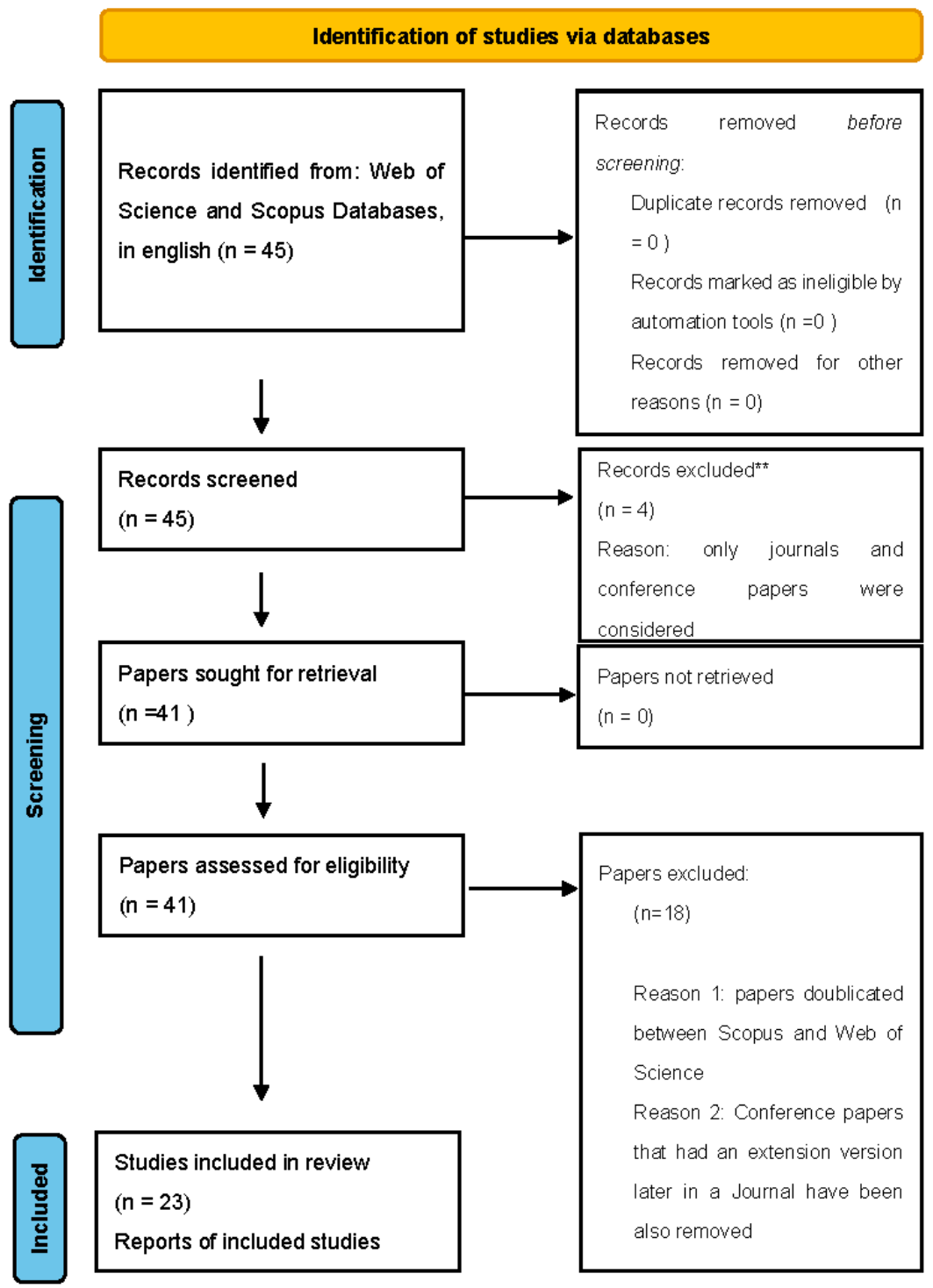

Figure 1. PRISMA 2020 flow diagram for systematic reviews.

To conduct this search, we used the Boolean string "Internet of service*" AND "business model*" and followed the steps as listed in Table 1, searching the Web of Science and Scopus bases. The use of the asterisk * right after the words "service" and "model" guarantees that the word appears in singular or in plural in the search results. Publication and journal databases were searched in English on 1 August 2021.

All co-authors looked at how the processes underpinning the review and made suggestions if necessary. From the first result of 45 papers, only journals and conference papers were considered, since peer review is a typical indicator of quality in research. This resulted in a total of 41 candidate papers.

We removed duplicated papers (14 papers in WoS were duplicated with findings from Scopus) and 4 conference papers that had an extended version in Journals, resulting in a total of 23 papers. 
Table 1. Boolean strings and including/excluding criteria for the research.

\begin{tabular}{|c|c|c|c|c|}
\hline \multirow{2}{*}{ Step } & \multirow{2}{*}{ String } & \multicolumn{3}{|c|}{ Finds } \\
\hline & & Scopus & WoS & Total \\
\hline$\# 1$ & "Internet of service*" AND "business model" & 30 & 15 & 45 \\
\hline \multirow[t]{2}{*}{$\# 2$} & "Internet of service" AND “business model*" (Journals and Conference papers only) & 26 & 15 & 41 \\
\hline & First selection: & \multicolumn{3}{|c|}{34 candidate papers } \\
\hline Step & Including/Excluding Criteria & \multicolumn{3}{|c|}{ Finds } \\
\hline \#3 & Removed duplicated papers (14 papers in WoS were duplicated with findings from Scopus) & \multicolumn{3}{|c|}{27} \\
\hline \multirow[t]{2}{*}{$\# 4$} & $\begin{array}{c}\text { Removed } 4 \text { conference papers that had an extended version in Journals. The respective Journal } \\
\text { versions were included. }\end{array}$ & \multicolumn{3}{|c|}{23} \\
\hline & Final selection: & \multicolumn{3}{|c|}{23 selected papers } \\
\hline
\end{tabular}

All the twenty-three studies were examined and distributed under categories of the problem they mainly address, their contributions and gaps. This answered the first research question regarding the state of the art of IoS. Next, the papers that focus on business were also categorized by fields of application to answer the second research question.

\section{Results}

The very first papers that explore the concept of IoS show that this kind of services have to combine and correlate information technology (IT), operational, and business aspects of forming the IoS [28]. The IoS consists of participants, an infrastructure for services, business models, and the services themselves [10]. Moreover, in order to form the Internet of Services, services have to be described in a way that the business dimension and the technology dimension gather [2].

From all these concepts, it is possible to infer that, besides the infrastructure to support the IT aspects, and the service operation that covers the operational aspects, the IoS needs a business application to exist. Nevertheless, as long the papers start exploring more the IoS-based services, we conclude that the IoS can have a business or social application depending on the participants and their goals.

As a result, we propose a taxonomy of categories that classify the IoS in four sub-areas, namely, infrastructure, service operation, business applications, and social applications.

Next, the selected studies have been divided into these four categories (Table 2). Each paper was placed in only one category according to its focus.

Table 2. List of selected studies by topic category.

\begin{tabular}{lccc}
\hline P1 & King and Grobbelaar (2020) [29]. Industry 4.0 and business modem innovation & $X$ \\
\hline P2 & Suseendran et al. (2020) [30]. Banking and FinTech embraced with IoT devices & & \\
\hline P3 & Cheng et al. (2018) [31]. Design for reducing device high load in industrial networks & $X$ & \\
\hline P4 & Lokshina et al. (2018) [32]. IoT and big data analysis services for third parties & & \\
\hline P5 & Vukanović (2018) [33]. The influence of ICT megatrends on global megatrends & $X$ \\
\hline
\end{tabular}


Table 2. Cont.

\begin{tabular}{|c|c|c|c|c|c|}
\hline \# & Selected Study & 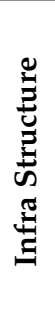 & 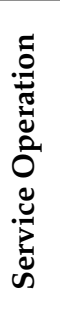 & 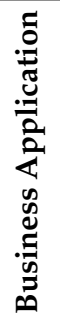 & 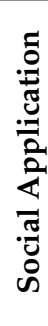 \\
\hline P6 & Cozmiuc and Petrisor (2018a) [34]. Industry 4.0 by Siemens: steps made today & & & $\mathrm{X}$ & \\
\hline P7 & Cozmiuc and Petrisor (2018) [35]. Industry 4.0 by Siemens: steps made next & & & $\mathrm{x}$ & \\
\hline P8 & Komarov et al. (2016) [36]. How IoT influences building social web & & & & $\mathrm{X}$ \\
\hline P9 & Zhang et al. (2016) [37]. Energy dialogue with industry 4.0 & & & $X$ & \\
\hline P10 & Chao (2016) [38]. E-services in e-business engineering & & $\mathrm{X}$ & & \\
\hline P11 & Komarov and Khokhlova (2015) [39]. Development of business model for social WoS & & & & $x$ \\
\hline $\mathrm{P} 12$ & Huang et al. (2013) [11]. BSNet network-based model for service-oriented business & & $x$ & & \\
\hline P13 & Armando et al. (2013) [40]. Trustworthy Opportunistic Access to the IoS & $\mathrm{X}$ & & & \\
\hline P14 & Papadakis et al. (2012) [41]. Leveraging the content of Social Networks & & & & $\mathrm{X}$ \\
\hline P15 & Arrieta (2012) [42]. Developing a tool for migration of non-SaaS applications to SaaS & $X$ & & & \\
\hline P16 & Weiner and Weisbecker (2011) [43]. Framework for design of business models in IoS & $\mathrm{X}$ & & & \\
\hline P17 & Kett (2010) [44]. A business model approach for service engineering in IoS & $\mathrm{X}$ & & & \\
\hline P18 & Ruiz-Agundez et al. (2010) [45]. Addressing the billing needs of Internet of Services & & $x$ & & \\
\hline P19 & Woitsch et al. (2010) [46]. Design, manage and execute service based on open models & $\mathrm{X}$ & & & \\
\hline P20 & Pasic (2010) [47]. Delivering trust, security, privacy for the internet of services & $\mathrm{x}$ & & & \\
\hline P21 & Wang et al. (2010) [48]. Monitoring model for business-oriented service operation & & $X$ & & \\
\hline $\mathrm{P} 22$ & Cardoso et al. (2009) [10]. Service engineering for the Internet of Services & & & $X$ & \\
\hline P23 & Cardoso (2009) [28]. The Internet of Services & $\mathrm{X}$ & & & \\
\hline
\end{tabular}

The categories are further explained according to the content of the selected studies and the contributions of current literature.

Table 3 brings the number of papers per topic category. Each category is better explored in the following sub-sections.

Table 3. Number of papers by topic category.

\begin{tabular}{lccc}
\hline & Topic Category & Number of Papers \\
\hline & \multicolumn{2}{c}{ Infrastructure } & 9 \\
\hline \multicolumn{2}{c}{ Service Operation } & & 4 \\
\hline \multirow{2}{*}{ Application } & & Business & \multicolumn{2}{c}{6} \\
\cline { 2 - 4 } & & Social & 4 \\
\hline
\end{tabular}

\subsection{Infrastructure}

An IT infrastructure for service delivery has to be provided to technically enable the business to participate in IoS [28] (P23).

Among the papers that focus on infrastructure, Cardoso [28] (P23) starts highlighting the importance of good technical infrastructure to make the IoS scalable and support business services. Pasic [47] (P20) explores technical solutions to the problems posed by managing 
security and trust. Trust, security, and privacy play a significant role for developing IoS solutions, since the services have to be loosely coupled and globally distributed [47] (P20).

Software-as-a-Service (SaaS) models are considered important features of the Internet of Services [49]. SaaS models offer a service-oriented and shared IT infrastructure that serves customers with service packages and flexible access via easy-to-use internet interfaces [50]. Arrieta [42] (P15) presents a tool supported methodology for business assessment when transforming a traditional service application to SaaS. Many characteristics need to be considered, such as architecture, platform, language, and the target SOA environment. Technically, SaaS applications are built up from SOA, but not all SOA applications are SaaS [42].

The literature review reveals a focus on a user-centric SOA in which the end-users would gain more empowerment for programming and exploiting the Web Services. However, the evolution of web-based service front ends falls short of end-user expectations and SOA remained on a technical layer hidden to end users [51].

IoT takes a prominent role in service applications, so the term IoS is often coupled with IoT. IoS is referred to as a globalization of service-oriented solutions, where Web services are offered by different providers [52]. When IoT starts to reproduce this scenario for millions of interconnected devices, a few issues start to be addressed in service domain as the lack of interoperability among such different sources of information. Known problems are the service composition, heterogeneity of physical communication, security, diversity of protocols and other challenges to effectively explore the communication between physical devices and enterprise software systems [53]. Software companies have been focused on standardizing the application programming interfaces (APIs) that enable basic commands and data transfer among IoT devices.

From a service composition perspective, room for improvement in artificial intelligencebased automatic service descriptions generation will require researchers to develop more ontologies and design more effective machine learning methods for semantic expression, classification, and matching. The process of defining requirements and determining the optimal selection of physical objects through web services could be described as a typical service composition problem that integrates IoT and IoS domains [54].

In regard to the challenge of interoperability among SOA applications, Cheng et al. [31] (P3) state it has been addressed by the Open Platform Communication Unified Architecture (OPC UA), a network transmission architecture that uses a peer-to-peer transmission method.

Besides the software, hardware devices and telecommunications also play an important role in the infrastructure for service delivery. Vukanović [33] (P5) highlights ICT-digital media megatrends, mainly the use of wearable sensors transmitting a large amount of data via mobile devices and computers. Armando et al. [40] (P13) address the adoption of the software-defined networking (SDN) as the potential solution to the on-demand connection among mobile devices, while Cheng et al. [31] (P3) propose a method for scheduling multiple periodic requests for reducing the high load of computing devices.

Scientific research in the following ICT fields will continue increasingly developing in the future: computer generated images, immersive and virtual reality, augmented reality, $5 \mathrm{G}$ wireless communications, ambient technology, IoT, nanorobotics, AI, geo targeting, 3D printing, predictive analytics, biometric sensors, big data analytics, etc. [33].

The theme of infrastructure goes beyond and reaches the software tools for business model development. Kett's work [44] (P17) focused on the need to develop different business models through the service description language, such as USDL, so that the business model could provide necessary information about services functionalities. Weiner and Weisbecker [43] (P16) defended the same argument introducing a business model ontology and a corresponding software approach to support the design of business model alternatives. Woitsch et al. [46] (P19) introduce the idea of the open models' paradigm applied for service models, aiming to motivate to share services models openly. 


\subsection{Service Operation}

The service operation contains two phases that are essential for the IoS: discovery/invocation and execution. Discovery and invocation refer to the technology used to find and request a service. The execution describes how the service is performed. In terms of execution, the services can be carried out by humans, with conjunction of human and automated devices, or solely automated. The difference in the IoS is that the discovery and invocation are always ICT-based [10].

"Designing services is not only a technical undertaking; it is the job of analyzing the business environment and business processes and identifying business functions that could be implemented as a service" [10].

Service operation studies the new Business/Operations Support System possibilities of, for instance, fraud management, customer usage, rating and billing, marketing, client resource management. Ruiz-Agundez et al. [45] (P18) mention the different pricing schemes that represent how the service client will be charged (e.g., pre-paid, post-paid, time-based, volume-based) and focus on fraud management and in the customer usage or experience.

When the IoT starts to play a more important role in service applications, the quality of service (QoS) gains focus, owing to the practical issues in integrating the commodity objects and the technology underlying the IoT become more challenging [53].

The QoS describes aspects used to evaluate the degree that a Web service meets specified quality requirements in a service request, such as usability, efficiency, reliability, and performance, and managerial aspects such as ownership, provider, contract, and payment [55]. Moreover, the subjective quality of the system perceived by the end-users is called quality of user experience (QoUE), also named quality of experience (QoE) [5]. QoS-based scoring algorithm rates each requirement by comparing its characteristics with the monitored service call records, while a QoE-based approach would focus on past user decisions [52]. Wang et al. [48] (P21) propose a metamodel to observe QoS metrics and implement a service monitor system to execute the monitoring.

During dynamic selection and composition, services are combined to create new added-value services to respond to the consumer's request. The environment creates the service request, so a service-oriented business ecosystem (SOBE) proposed by Huang et al. [11] (P12) could translate it into abstract composition requests that refer the service process and the QoS of every service. Chao [38] (P10) raises that domain ontologies are needed to provide a coherent and context-rich environment and method. Such operation will support discovery and intelligent approaches based on AI to classify services to facilitate service matching. AI is also the approach used by Bucchiarone et al. [15] to solve composition problems of real-world complexity in dynamic applications that heavily depend on the execution environment's run-time parameters.

\subsection{Business Applications}

In the IoS ecosystem, service providers, organizations and enterprises offer business services. Business services respond to requests from consumers or other services.

The studies previously categorized in business applications topic were distributed by fields of applications, according to the focus of the respective papers (Table 4).

$>\quad$ Manufacture/Industry 4.0

Industry 4.0 could be divided into CPS (Cyber-physical systems), IoT, IoS, and the Smart Factory [1].

Because innovation industries are challenged by high mix, high volume, and high complexity, Cozmiuc and Petrisor [35] (P7) research how Industry 4.0 can support integrated supply chains and eco-systems of partners that bring new business models. In addition, King and Grobbelaar [29] (P1) corroborate that future research may explore how servitization business models can be used and designed to embrace Industry 4.0.

For Cozmiuc and Petrisor [34] (P6), the shopfloor will become a network of selforganizing decision-making agents by transforming all machines into CPS, which form the 
IoT and IoS within Industry 4.0. The idea matches the concept of IoS as a future internet allowing an ad hoc configuration of services, not relying on pre-determined network infrastructure [56].

Opportunities for new business models also emerge by means of new energy utilization technologies such as electric heating equipment, electrified rail transit, electric vehicles, etc. [57]. Zhang et al. [37] (P9) promote the deployment of smart grid in substitution of electricity for direct consumption of primary energy such as coal, gasoline, and diesel. Coupled with CPS, IoT and IoS, the formation of smart grid and added value streams gradually evolve towards global energy interconnection by opening a dialogue with Industry 4.0.

Table 4. Selected studies by field of application in business.

\begin{tabular}{|c|c|c|c|}
\hline \multirow[b]{2}{*}{ Selected Study } & \multicolumn{3}{|c|}{ Fields of Business Applications } \\
\hline & $\begin{array}{l}\text { Manufacture } \\
\text { (Industry 4.0) }\end{array}$ & $\begin{array}{c}\text { Financial } \\
\text { Services }\end{array}$ & Marketplace \\
\hline King and Grobbelaar (2020) [29] (P1) & $X$ & & \\
\hline Suseendran et al. (2020) [30] (P2) & & $X$ & \\
\hline Cozmiuc and Petrisor (2018a) [34] (P6) & $x$ & & \\
\hline Cozmiuc and Petrisor (2018b) [35] (P7) & $x$ & & \\
\hline Zhang et al. (2016) [37] (P9) & $x$ & & \\
\hline Cardoso et al. (2009) [10] (P22) & & & $X$ \\
\hline
\end{tabular}

$>$ Financial services (Fintech)

FinTech introduces a new service of tools and products for the emergent businesses through the IoS. Banking FinTech works with capital valuation, trading, investment, and asset valuation and provides new improving accounting systems compared to existing financial technology. The motivation of banking FinTech service is to reduce the human errors and increase banking business transaction and accessing [30] (P2).

As per Suseendran et al. [30] (P2), the banking and financial sectors create a new way of collecting valuable information about the customers through IoT sensor devices using smartphones. The bank can analyze the usage of services to increase and decrease the points of presence. Additionally, since customer information is stored in devices, the bank uses this opportunity to help in identifying customer's business needs. The IoS is a worldwide connector; therefore, the cyber attacker can easily access the targeted user's data because third-party services are unprotected. There are positive features in innovative financial technology: blockchain and crypto currencies, an alternative payment system, and FinTech technology and banking solutions. Nevertheless, the threats related to the FinTech essentials are adverse effects in the FinTech financial service sector.

$>$ Marketplaces

Marketplaces for products enable business interaction between providers and consumers of physical goods. Cardoso et al. [10] (P22) explain that "in the IoS vision, services are tradable goods that their providers can offer on service marketplaces to make them available for potential consumers". On a service marketplace, different service providers that previously agree with the contractual rules may be accepted to offer their services. Providers may vary in size and specialization, enabling a competing and collaborating ecosystem of services.

Startup companies have been producing and bringing to the marketplace innovative goods and services. They generate value added in the form of services that they expose to the community. These services may be purchased and consumed, in some form, by the public or may be further aggregated by other service providers [58]. 


\subsection{Social Applications}

There are applications that provide other aspects of the social dynamics to the end users and can also be transformed into services over the internet [41].

The studies previously categorized in social applications topic were distributed according to their fields (Table 5).

Table 5. Selected studies by field of social application.

\begin{tabular}{|c|c|c|c|}
\hline \multirow{2}{*}{ Selected Study } & \multicolumn{3}{|c|}{ Fields of Social Applications } \\
\hline & Healthcare & Smart Environment & Social Networks \\
\hline Lokshina et al. (2018) [32] (P4) & $x$ & $X$ & \\
\hline Komarov et al. (2016) [36] (P8) & & $x$ & $x$ \\
\hline Komarov and Khokhlova (2015) [39] (P11) & & $x$ & \\
\hline Papadakis et al. (2012) [41] (P14) & & & $X$ \\
\hline
\end{tabular}

$>$ Healthcare

Healthcare is one of the main categories of organizations that can benefit from ICT advances as it will be personalized and involve the use of wearable sensors transmitting a large amount of patient data via mobile devices and computers [32] (P4).

Moreover, the trend of an ageing population will result in increased need for healthcaremonitoring ICT solutions for older people manage their health and consequently prevent health decline and detect near-fall events [59]. There are three key tasks facing the global healthcare system: reducing rising costs, improving quality and results, and expanding access [33].

Lokshina et al. [32] (P4) assess business opportunities applying IoT and Big Datadriven services for third parties. When massive amounts of data become accessible and understandable, the health organizations can subsequently use them, and the implications are enormous for civic life and personal health. Hospitals collect a large amount of patient data, so that information can be connected to a central or aggregated intelligencemanagement structure that allow for deep, complex analysis. The distribution of drugs and monitoring of blood pressure is observed regularly, so this data could be channeled into activities to improve care, reduce the length of stays in the hospital, and lower the transmission of diseases and infection rates.

Healthcare systems give people the opportunity to access their own health data through smartphone and collaborate in their own healthcare process, while provide public health surveillance [59].

\section{$>$ Smart Environment}

Smart Environment raises important social applications, and governments are interested in using the latest technologies to promote the best social climate to their citizens. It includes smart homes, smart cities, office, and plant, all integrated into the environment [32] (P4).

Komarov and Khokhlova [39] (P11) focus on IoS connection with the IoT. The IoS suggests that every connected system has its own API, and a large amount of data produced by things can be shared with the data consumers, i.e., apps, people, or other items. Komarov et al. [36] (P8) bring an IoT influenced smart home business model in which a protocol connects the related devices (refrigerators, washers, microwaves, smartphones, TVs, etc.) and opens access for other vendors to get on board. Such a model can be expanded to cover home-energy, or "eco-home applications" through the partnerships with third-party service providers.

Lokshina et al. [32] (P4) also raise business opportunities in smart environment through the IoT and big data. Information platforms offering comprehensive public transportation information can be developed using open data released by the government together with data collected from the Internet to provide up-to-date information for users. A large customer base can be built for use with advertising and other add-on features. Using a 
digital business model, the application can be offered at no cost for users with its main source of revenue from mobile advertisements. Collaborators include complementary service providers, such as food delivery and taxis, which rely on location-based technology and generate revenue through service charge.

\section{$>$ Social Networks}

Social networks are a potential market for services owing to the volumes of amateur content generated. Moreover, the abundance of subjective content of social network makes it ideal for mining the opinion of its users towards products or services. Papadakis et al. [41] (P14) list possible applications for providers that wish to raise resources from social networks for new services: journalists can monitor the activity of a group of users who are related to a particular topic or a location; producers can cast supporting actors for a play taking advantage of the fact that in social networks the users already provide information and photographs; TV commercial producers may locate a place where they can have the shooting, sending out the description and getting back options close to the target location.

Users of social media typically gather into communities based on some common interests. Their interactions inside these online communities follow several interesting patterns. Komarov et al. [36] (P8) provided an agent-based model simulation showing that companies might manipulate human behavioral patterns through smart things cooperation and social effects. As a result, a required usage setting trend could be created, leading to a business model of a social web of services, which would be the network of shared services by people and devices via social networks.

However, social networks present challenges to the applicability of traditional sentiment analysis techniques, due to their sparse, multilingual, and noisy content [41]. In addition, information security, information privacy and legitimacy are obstacles that must also be considered [36] (P8).

\section{Discussion}

Through this systematic literature review, we aimed to answer two main research questions: RQ1. What is the state of the art of Internet of Services-based business models?

To answer the first research question, we analyzed the selected studies and their developments in IoS by dividing them into four categories according to their focus: infrastructure, service operation, business applications, and social applications.

As it is closely-related with technologies paradigms, the review reflects important scenario movements on the Internet environment and on ICT over the past decade.

By offering business functions as web services, it is possible to "break up enterprise boundaries and harmonize services of diverse development platforms. Business services can be made openly available and reusable for supporting collaborative business processes by service orchestration or choreography" [60].

From the categorization in Table 1, it is noticed that the focus of the first papers was much more on IT infrastructure. Although the term "business model" was often mentioned in the papers, the content was mainly on SOA, software functions, and how web services should work through the applications [11,42-44,46,47] (P12, P15, P16, P17, P19, $\mathrm{P} 20)$, likely the technical pre-requisites to make the business feasible but not a discussion on the business or IoS-based business model.

Apart from technical aspects, important questions arise regarding who the suppliers of such services are, how the value capture guarantee that billing and revenue are well structured, and which are more sustainable alternatives for suppliers of such services [61].

From a business perspective, there is a need of understanding how value is created through business services. "A special emphasis has to be given to the generation of new business models for all stakeholders (i.e., service providers, aggregators, and consumers) and corresponding incentive mechanisms" [10] (P22). However, the value creation, which is one of the main functions of a business model [20], rarely appears among the selected papers that address the business applications. 
For Komarov and Khokhlova [39] (P11), the phenomena of the IoS concern different spheres, yet the focus has been placed on its connection with the IoT. Bachara et al. [53] and Chao [38] (P10) state that the IoS is an extension of the IoT, poised to take e-service markets to the next stage.

While IoT emerged in the business literature [62-64], the IoS research remained among the developers' software engineers [49], focused on the infrastructure and appropriate programming codes to develop applications [15,51,52,65].

Although the focus changed from the pure IT infrastructure to a business view in the studies that cover the business and social applications, the authors still emphasize the services being potentialized by the IoT and how IoT is an important infrastructure for IoS $[30,32,36,39]$ (P2, P4, P8, P11). In the Industry 4.0 scenario, the CPS gains the same relevance to form the IoS $[29,34,35]$ (P1, P6, P7). The studies explain the business or social application through the technological aspect but lack in the business and organizational aspects.

By analyzing the types of business model studied by Øverby and Audestad [25], the ones that have already a digital mediation platform and exploit the network collaboration, could apply to IoS if some other IoS features are explored. One example is Airbnb, a $\mathrm{C} 2 \mathrm{C}$ digital platform that would be stronger if they applied some of the IoS features to shape their existing business model. Additionally, the different payment methods could be combined for value capture in an IoS-based business model, such as subscription, pay-per-use, or ad-based free.

Considering the low number of papers that correlate IoS and business model, there is still a gap in understanding how to construct an IoS-based business model. There is a lack of a detailed view of the business model to support the concept of IoS in creating, delivering, and capturing value to customers. Efforts are still focused on the IT level. Little work has been completed at the business level.

RQ2. What is their classification based on application field?

Regarding the application fields, it is noticed that the role IoS, the heartwood of Industry 4.0, is not entirely clear in this scenario. It would be important to assess how IoS is applied for advanced manufacturing. Manufacturing progressive concepts such as digitalization, standardization, flexibility, customization, real-time responsibility, predictive maintenance, are moving to Industry 4.0, which involves decision making, selfoptimization, self-configuration. However, further research and development still needs to be undertaken.

There is a line of research focusing on digitalization and servitization within Industry 4.0. Frank et al. [66] study the connection between Industry 4.0 and servitization, presenting a conceptual framework that analyze the role of digitalization and servitization within the product-firm, while Gebauer et al. [67] discuss the paradox of firms that invest in digitalization and servitization but not earn the expected return. It happens when firms do not study the business model well and all its components, mainly the value proposition. While digitalization and servitization combine digital and services capabilities to facilitate internal growth, the IoS covers the external growth, which is an important view that companies neglect while innovating their business models [67]. Coupled with CPS and IoT, IoS would be a business model proposal that is still being researched and developed to reach Industry 4.0 [35] (P7). R King and Grobbelaar [29] (P1) corroborate that, instead of only firm-centric models as servitization and digitalization, researchers should consider a business model to adopt an ecosystem perspective.

Healthcare and Smart Environment appear as important IoS domains for social applications [32,36,39] (P4, P8, P11). In most countries, one of the largest providers of services is the government. Governments are interested in using the latest technologies to promote the best social climate for their citizens. However, the legal framework of the latest technologies is still considered rather vague or absent to a certain extent. Such issues as standardization, service design architecture and models, as well as data privacy and security create management and governance problems. 
The technological advances may also change the future of food production and bring more sustainable alternatives. The innovative systems driven by the CPS, IoT, and IoS start to evolve the rural food production, allowing the automation, communication and digitalization of value chains [68]. The solutions already in place are IoT-based, which enable the smart logistics and traceability with applications for controlled environment and food supply chain tracking $[69,70]$. An opportunity in this field would be mapping the platforms used by the different stakeholders to propose new services through collaborative networks [71].

From a social applications perspective, the papers that mention the IoS as a trend for business models are conceptual and focus on IoT as an important infrastructure for social applications but do not clarify the IoS role on such business models. Important to shed a light on IoS contribution for business model construction.

\section{Research Agenda}

Questions around the mapping between the real world of business models and the IoS-based services are still unresolved. Although there is some correlation between business model and IoS in the literature, such intersection is still unexplored. Most research focuses on the infrastructure needed for the IoS environment. Moreover, the papers that describe the IoS are mainly theoretical and bring a few examples of business and social applications.

Based on the presented literature review, we propose a research agenda. The research agenda is composed of two main research streams: (1) exploring the business model metacomponents for an IoS adoption, and (2) exploring the IoS application fields. The two research streams are also presented in Table 6 with the respective supporting literature.

\subsection{Exploring Business Models Meta-Components for IoS Adoption}

Future research could investigate the development of business models by organizations for an effective IoS adoption. Figure 2 shows the four sub-areas of IoS proposed in the presented study (infrastructure, service operation, business applications and social applications), interlocking with the business model's four meta-components (value proposition, value creation, value delivery and value capture) [20]. The intersection is the IoS-based business model, which can be better explored in future research.

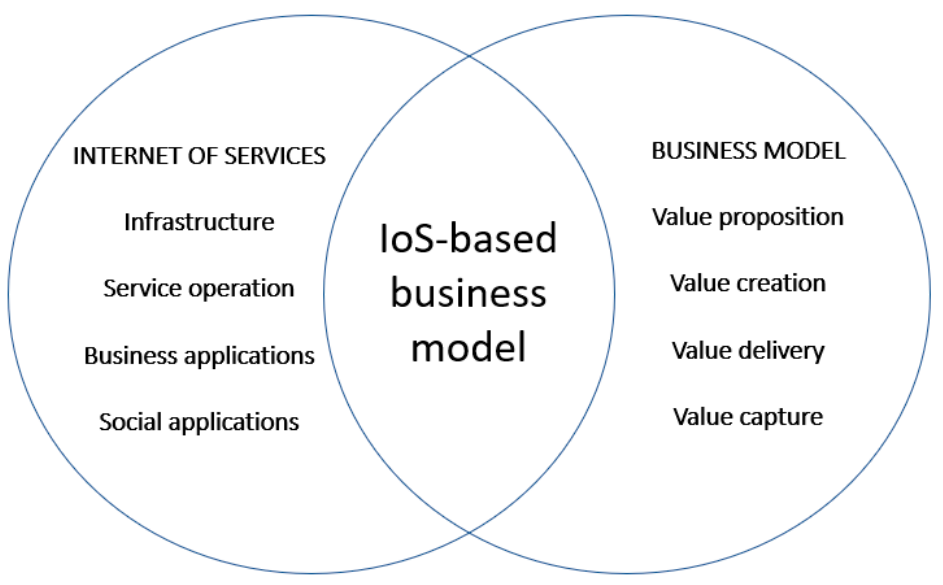

Figure 2. IoS-based business model.

The widely accepted Business Model Canvas [24], which covers the four areas placed in the second circle of Figure 2, is rarely associated with the IoS. In the present review, considering the papers that explore business or social applications, only Komarov et al. [36] (P8) presented a Business Model Canvas which is an IoT-influenced Smart Home business model. The main goal of their research was to check how the raising number of internetconnected devices influence users. 
A service ecosystems perspective on business models proposes that "service marketing strategy be less focused on traditional marketing and instead work on the relationship and conversation among the involved stakeholders. A collaborative service-oriented approach has to be embraced to actively explore the rich strategic implication from a service ecosystem" [8]. Consequently, studies that explore how the enterprises are innovating in their business models' value proposition, creation, and delivery for a service ecosystem, allow the expansion of this theme.

Considering the social applications emerging as an IoS domain, another possible future study is the elaboration of research about the social motivations behind a business model innovation. Moreover, analyzing what the customers want and need becomes crucial to develop an IoS-based business model that meets the requirements for a best service delivery. Companies should offer services and solutions that more effectively address their customers' needs [67], always considering their data privacy and security to avoid creating management and governance problems.

\subsection{Exploring the IoS' Application Fields}

Future studies could promote the IoS expansion in any field that have not yet been assessed in relation to IoS-based business models, considering the service dominance is not restricted to the more traditional services as education, hospitality, and healthcare. It also appears in traditional product-oriented industries such as the manufacturing, building sector, and agriculture.

In traditional service sector, there is a range of applications. In healthcare, "the IoS, as a new concept of Internet evaluation, depends not only on technological solutions but also on service innovations in the field of new value propositions where a patient-centered model is needed. Such a model would consider patient preferences, values, and the need for information as the leading characteristics of care. Patient and medical unit engagement is an essential prerequisite for the new value proposition development process" [72]. Similar research topics could be studied in other services, such as education.

In manufacturing, the IoS role is not totally clear and there are challenges in addressing an IoS-based business model. Jiao et al. [73] question "how to customize products and services to user requirements while producing products of "zero lot size" and "mass production costs". Despite the relevance of the IoS as a pillar for the Industry $4.0[1,6]$, the relationship between IoS and business model is not deeply covered by the current scientific research. Although there are theoretical archetypes for data-driven business models in Industry 4.0 [74], they can be further developed to address the IoS and its features.

Table 6. Research agenda.

\begin{tabular}{|c|c|c|}
\hline Research Stream & Research Question & Supporting Literature \\
\hline \multirow{2}{*}{$\begin{array}{l}\text { Exploring the business model } \\
\text { meta-components for IoS adoption }\end{array}$} & $\begin{array}{l}\text { How to adapt the business model and its structure for } \\
\text { applying IoS, regarding value proposition, value } \\
\text { creation, value delivery and value capture? }\end{array}$ & {$[8,10,25,74]$} \\
\hline & $\begin{array}{l}\text { How the shift toward IoS-based business model meets } \\
\text { social motivations and customer value proposition } \\
\text { while being compliant with data privacy and security? }\end{array}$ & {$[36,41]$} \\
\hline \multirow{3}{*}{ Exploring the IoS' application fields } & $\begin{array}{c}\text { Which would be an IoS-based business model archetype } \\
\text { in traditional service sectors like healthcare } \\
\text { and education? }\end{array}$ & {$[32,72]$} \\
\hline & $\begin{array}{l}\text { How to expand the business model in manufacturing } \\
\text { sector for an IoS ecosystem perspective, shaping the } \\
\text { firm-centric models as servitization and digitalization? }\end{array}$ & {$[29,35,67,73,74]$} \\
\hline & $\begin{array}{l}\text { What is being applied for innovations toward IoS-based } \\
\text { business model in agri-business sector? }\end{array}$ & {$[68,71]$} \\
\hline
\end{tabular}


In agri-business, Lezoche et al. [71] highlight the diversity of stakeholders integrating agri-food chains, and suggest that an integrated platform could support the several players in delivering new valuable services.

\section{Conclusions}

The IoS is seen as a new ecosystem where service providers and consumers explore their business networks for service provision and consumption. IoS has characteristics that distinguish it, which is the foundation in SOA and modularity, besides a context-aware expected behavior that places it in a Future Internet scenario. Although the IoS plays an important role on business through an innovative way of service offering, there is a gap in scientific literature in covering IoS-based business models and this is what the present review aims to exploit.

A systematic search methodology allowed us to identify 23 studies that were published in journals or proceedings that discuss advances in IoS domain. As a first contribution of the presented study, we proposed a taxonomy to classify the IoS in sub-areas which are: infrastructure, service operation, business applications, and social applications. The selected studies were categorized in these four sub-areas, and then by the application fields. Research could also derive the archetypes of IoS-based business models across the industries, what is an opportunity for future work.

The review showed that most of papers explore the technical infrastructure that will allow the services being offered through the Internet, but lack on a detailed view of an IoSbased business model to support the concept of IoS in creating, delivering, and capturing value to customers. There is room for future research in investigating the role that IoS plays in business, not only coupled with IoT and CPS as the literature often mentions it. Moreover, it is also important to explore other application fields where IoS appears rather than Industry 4.0. The study highlights the opportunities of IoS applications in different fields and present a research agenda for future studies on IoS-based business models.

Author Contributions: Conceptualization, J.Z.R. and R.F.G.; methodology, J.Z.R., R.F.G. and N.K.; validation and research directions, J.Z.R., R.F.G., M.T.d.S. and N.K.; writing-original draft preparation, J.Z.R.; writing—review and editing, J.Z.R., R.F.G., M.T.d.S. and N.K.; supervision, R.F.G.; funding acquisition, J.Z.R. All authors have read and agreed to the published version of the manuscript.

Funding: This research was funded in part by the Coordenação de Aperfeiçoamento de Pessoal de Nivel Superior-Brasil (CAPES)—Finance Code 001.

Institutional Review Board Statement: Not applicable.

Conflicts of Interest: The authors declare no conflict of interest.

\section{References}

1. Hofmann, E.; Rüsch, M. Industry 4.0 and the current status as well as future prospects on logistics. Comput. Ind. 2017, 89, 23-34. [CrossRef]

2. Wahlster, W.; Grallert, H.-J.; Wess, S.; Friedrich, H.; Widenka, T. (Eds.) Towards the Internet of Services: The THESEUS Research Program; Springer International Publishing: Cham, Switzerland, 2014. [CrossRef]

3. Bouncken, R.B.; Kraus, S.; Roig-Tierno, N. Knowledge- and innovation-based business models for future growth: Digitalized business models and portfolio considerations. Rev. Manag. Sci. 2019, 15, 1-14. [CrossRef]

4. Xu, H.; Wang, X.; Wang, Y.; Li, N.; Tu, Z.; Wang, Z.; Xu, X. Domain Priori Knowledge based Integrated Solution Design for Internet of Services. In Proceedings of the 2020 IEEE International Conference on Services Computing (SCC), Beijing, China, 7-11 November 2020; pp. 446-453. [CrossRef]

5. Balakrishnan, S.M.; Sangaiah, A.K. Integrated QoUE and QoS approach for optimal service composition selection in internet of services (IoS). Multimed. Tools Appl. 2017, 76, 22889-22916. [CrossRef]

6. Alcácer, V.; Cruz-Machado, V. Scanning the Industry 4.0: A Literature Review on Technologies for Manufacturing Systems. Eng. Sci. Technol. Int. J. 2019, 22, 899-919. [CrossRef]

7. Hermann, M.; Pentek, T.; Otto, B. Design Principles for Industrie 4.0 Scenarios. In Proceedings of the 201649 th Hawaii International Conference on System Sciences (HICSS), Koloa, HI, USA, 5-8 January 2016; pp. 3928-3937. [CrossRef]

8. Wieland, H.; Hartmann, N.N.; Vargo, S.L. Business models as service strategy. J. Acad. Mark. Sci. 2017, 45, 925-943. [CrossRef] 
9. Grabowska, S.; Gajdzik, B.; Saniuk, S. The Role and Impact of Industry 4.0 on Business Models. In Sustainable Logistics and Production in Industry 4.0; Grzybowska, K., Awasthi, A., Sawhney, R., Eds.; Springer International Publishing: Cham, Switzerland, 2020; pp. 31-49. [CrossRef]

10. Cardoso, J.; Voigt, K.; Winkler, M. Service Engineering for the Internet of Services. In Enterprise Information Systems; Filipe, J., Cordeiro, J., Eds.; Springer: Berlin/Heidelberg, Germany, 2009; pp. 15-27. [CrossRef]

11. Huang, K.; Fan, Y.; Tan, W.; Qian, M. BSNet: A network-based framework for service-oriented business ecosystem management: Network-Based Framework for SOBE Management. Concurr. Comput. Pract. Exp. 2013, 25, 1861-1878. [CrossRef]

12. Schroth, C.; Janner, T. Web 2.0 and SOA: Converging Concepts Enabling the Internet of Services. IT Prof. 2007, 9, 36-41. [CrossRef]

13. Moreno-Vozmediano, R.; Montero, R.S.; Llorente, I.M. Key Challenges in Cloud Computing: Enabling the Future Internet of Services. IEEE Internet Comput. 2013, 17, 18-25. [CrossRef]

14. Cardoso, J.; Barros, A.; May, N.; Kylau, U. Towards a Unified Service Description Language for the Internet of Services: Requirements and First Developments. In Proceedings of the 2010 IEEE International Conference on Services Computing, Miami, FL, USA, 5-10 July 2010; pp. 602-609. [CrossRef]

15. Bucchiarone, A.; Marconi, A.; Pistore, M.; Raik, H. A context-aware framework for dynamic composition of process fragments in the internet of services. J. Internet Serv. Appl. 2017, 8, 6. [CrossRef]

16. Osterwalder, A.; Pigneur, Y.; Tucci, C.L. Clarifying Business Models: Origins, Present, and Future of the Concept. Commun. Assoc. Inf. Syst. 2005, 16, 1. [CrossRef]

17. Zott, C.; Amit, R.; Massa, L. The Business Model: Recent Developments and Future Research. J. Manag. 2011, 37, 1019-1042. [CrossRef]

18. Foss, N.J.; Saebi, T. Fifteen Years of Research on Business Model Innovation: How Far Have We Come, and Where Should We Go? J. Manag. 2017, 43, 200-227. [CrossRef]

19. Schiavi, G.S.; Behr, A. Emerging technologies and new business models: A review on disruptive business models. Innov. Manag. Rev. 2018, 15, 338-355. [CrossRef]

20. GüNzel, F.; Holm, A.B. One size does not fit all-Understanding the front-end and back-end of business model innovation. Int. J. Innov. Manag. 2013, 17, 1340002. [CrossRef]

21. Remane, G.; Hanelt, A.; Tesch, J.F.; Kolbe, L.M. The business model pattern database-A tool for systematic business model innovation. Int. J. Innov. Manag. 2017, 21, 1750004. [CrossRef]

22. Kerzel, U. Enterprise AI Canvas Integrating Artificial Intelligence into Business. Appl. Artif. Intell. 2021, 35, 1-12. [CrossRef]

23. Cardeal, G.; Höse, K.; Ribeiro, I.; Götze, U. Sustainable Business Models-Canvas for Sustainability, Evaluation Method, and Their Application to Additive Manufacturing in Aircraft Maintenance. Sustainability 2020, 12, 9130. [CrossRef]

24. Osterwalder, A.; Pigneur, Y. Business Model Generation: A Handbook for Visionaries, Game Changers, and Challengers; Flash Reproductions: Toronto, ON, Canada, 2010.

25. Øverby, H.; Audestad, J.A. Introduction to Digital Economics: Foundations, Business Models and Case Studies; Springer International Publishing: Cham, Switzerland, 2021. [CrossRef]

26. Kitchenham, B. Procedures for Performing Systematic Reviews; Keele University: Keele, UK, 2004; pp. 1-26.

27. Page, M.J.; McKenzie, J.E.; Bossuyt, P.M.; Boutron, I.; Hoffmann, T.C.; Mulrow, C.D.; Shamseer, L.; Tetzlaff, J.M.; Akl, E.A.; Brennan, S.E.; et al. The PRISMA 2020 statement: An updated guideline for reporting systematic reviews. BMJ 2021, 88, 105906. [CrossRef]

28. Cardoso, J. The Internet of Services. In Proceedings of the ICSOFT 2009-4th International Conference on Software and Data Technologies, Sofia, Bulgaria, 26-29 July 2009.

29. King, S.; Grobbelaar, S.S. Industry 4.0 and Business Model Innovation: A Scoping Review. In Proceedings of the 2020 IEEE International Conference on Engineering, Technology and Innovation (ICE/ITMC), Cardiff, UK, 15-17 June 2020; pp. 1-8. [CrossRef]

30. Suseendran, G.; Chandrasekaran, E.; Akila, D.; Sasi Kumar, A. Banking and FinTech (Financial Technology) Embraced with IoT Device. In Data Management, Analytics and Innovation; Sharma, N., Chakrabarti, A., Balas, V.E., Eds.; Springer: Singapore, 2020; pp. 197-211. [CrossRef]

31. Cheng, T.-S.; Lee, K.-M.; Lu, Y.-H.; Huang, M.-K.; Hong, W.-T. Design and Implement for Reducing the Temporary High Load of Device in Industrial Networks. In Proceedings of the 2018 International Conference on System Science and Engineering (ICSSE), New Taipei, Taiwan, 28-30 June 2018; pp. 1-4. [CrossRef]

32. Lokshina, I.V.; Lanting, C.J.M.; Durkin, B.J. IoT- and Big Data-Driven Data Analysis Services for Third Parties, Strategic Implications and Business Opportunities. Int. J. Soc. Ecol. Sustain. Dev. 2018, 9, 34-52. [CrossRef]

33. Vukanović, Z. The influence of ICT megatrends on global megatrends. Informatologia 2018, 51, 43-52. [CrossRef]

34. Cozmiuc, D.; Petrisor, I. Industrie 4.0 by Siemens: Steps Made Today. J. Cases Inf. Technol. 2018, 20, 30-48. [CrossRef]

35. Cozmiuc, D.; Petrisor, I. Industrie 4.0 by Siemens: Steps Made Next. Available online: https://www.researchgate.net/profile/ Diana-Cozmiuc/publication/322228184_Industrie_40_by_Siemens_Steps_Made_Next/links/60e59ee792851c2b83e595fa/ Industrie-40-by-Siemens-Steps-Made-Next.pdf (accessed on 29 January 2022).

36. Komarov, M.; Konovalov, N.; Kazantsev, N. How Internet of Things Influences Human Behavior Building Social Web of Services via Agent-Based Approach. Found. Comput. Decis. Sci. 2016, 41, 197-210. [CrossRef]

37. Zhang, X.; Jianing, L.; Hao, F. Global Energy Interconnection Dialogue Industry 4.0. Power Syst. 2016, 40, 1607-1611. 
38. Chao, K.-M. E-services in e-business engineering. Electron. Commer. Res. Appl. 2016, 16, 77-81. [CrossRef]

39. Komarov, M.M.; Khokhlova, A.D. Development of a business model for Social Web of Services. Bus. Inform. 2015, 2, 20-29.

40. Armando, A.; Castiglione, A.; Costa, G.; Fiore, U.; Merlo, A.; Verderame, L.; You, I. Trustworthy Opportunistic Access to the Internet of Services. In Information and Communicatiaon Technology; Mustofa, K., Neuhold, E.J., Tjoa, A.M., Weippl, E., You, I., Eds.; Springer: Berlin/Heidelberg, Germany, 2013; pp. 469-478. [CrossRef]

41. Papadakis, G.; Tserpes, K.; Sardis, E.; Kardara, M.; Papaoikonomou, A.; Aisopos, F. Social media meta-API: Leveraging the content of social networks. In Proceedings of the 21st International Conference Companion on World Wide Web-WWW'12 Companion, Lyon, France, 16-20 April 2012; ACM Press: Lyon, France; p. 271. [CrossRef]

42. Arrieta, L.O.-E. From Software as a good to software as a service: Preparing the evolution of software products into the cloud. In Proceedings of the 2012 IEEE 6th International Workshop on the Maintenance and Evolution of Service-Oriented and Cloud-Based Systems (MESOCA), Trento, Italy, 24-24 September 2012; pp. 58-59. [CrossRef]

43. Weiner, N.; Weisbecker, A. A Business Model Framework for the Design and Evaluation of Business Models in the Internet of Services. In Proceedings of the 2011 Annual SRII Global Conference, San Jose, CA, USA, 29 March-2 April 2011; pp. 21-33. [CrossRef]

44. Kett, H. A Business Model Approach for Service Engineering in the Internet of Services. Int. J. Serv. Sci. Manag. Eng. Technol. 2010, 2, 1-8.

45. Ruiz-Agundez, I.; Bringas, P.G.; Penya, Y.K. Addressing the Billing Needs for the Internet of Services and Things. Available online: https://www.researchgate.net/profile/Pablo-Bringas-2/publication/225308089_Addressing_the_Billing_Needs_for_ the_Internet_of_Services_and_Things/links/00b7d5357acd13cb2a000000/Addressing-the-Billing-Needs-for-the-Internet-ofServices-and-Things.pdf (accessed on 29 January 2022).

46. Woitsch, R.; Utz, W.; Tektonidis, D. Design, manage and execute services based on Open Service Models. In Proceedings of the eChallenges e-2010 Conference, Warsaw, Poland, 27-29 October 2010.

47. Pasic, A. Delivering Building Blocks for Internet of Services: Trust, Security, Privacy and Dependability. In New Network Architectures; Tronco, T., Ed.; Springer: Berlin/Heidelberg, Germany, 2010; pp. 205-214. [CrossRef]

48. Wang, Z.; Zhao, Z.; Qi, K. A Model-Driven Approach for Business-Oriented Monitoring of Service Operation. In Proceedings of the 2010 International Conference on Service Sciences, Hangzhou, China, 13-14 May 2010; pp. 231-236. [CrossRef]

49. Passani, A.; Monacciani, F.; Van Der Graaf, S.; Spagnoli, F.; Bellini, F.; Debicki, M.; Dini, P. SEQUOIA: A methodology for the socio-economic impact assessment of Software-as-a-Service and Internet of Services research projects. Res. Eval. 2014, 23, 133-149. [CrossRef]

50. Benlian, A.; Hess, T.; Buxmann, P. Drivers of SaaS-Adoption-An Empirical Study of Different Application Types. Bus. Inf. Syst. Eng. 2009, 1, 357-369. [CrossRef]

51. Lara, J.A.; Lizcano, D.; Martínez, M.A.; Pazos, J. Developing front-end Web 2.0 technologies to access services, content and things in the future Internet. Future Gener. Comput. Syst. 2013, 29, 1184-1195. [CrossRef]

52. Papageorgiou, A.; Miede, A.; Schulte, S.; Schuller, D.; Steinmetz, R. Decision support for Web service adaptation. Pervasive Mob. Comput. 2014, 12, 197-213. [CrossRef]

53. Bachara, P.; Brzoza-Woch, R.; Długopolski, J.; Nawrocki, P.; Ruta, A.; Zaborowski, W.; Zieliński, K. Construction of hardware components for the internet of services. Comput. Inform. 2015, 34, 911-940.

54. Dumitrache, I.; Sacala, I.S.; Moisescu, M.A.; Caramihai, S.I. A Conceptual Framework for Modeling and Design of Cyber-Physical Systems. Stud. Inform. Control 2017, 26, 325-334. [CrossRef]

55. Tran, V.X.; Tsuji, H. A Survey and Analysis on Semantics in QoS for Web Services. In Proceedings of the 2009 International Conference on Advanced Information Networking and Applications, Bradford, UK, 26-29 May 2009. [CrossRef]

56. Qiu, T.; Chen, N.; Li, K.; Qiao, D.; Fu, Z. Heterogeneous ad hoc networks: Architectures, advances and challenges. Ad Hoc Netw. 2017, 55, 143-152. [CrossRef]

57. Yang, Y.; Qiu, F.; Zhao, J.; Zeng, M.; Wang, Y.; Sun, C. Analysis of the Relationship between the Operation Characteristics of Global Energy Internet and the Influencing Factors under the Background of Big Data and Big Energy. In Proceedings of the 1st International Symposium on Economic Development and Management Innovation (EDMI 2019), Hohhot, China, 28-29 July 2019; Atlantis Press: Amsterdam, The Netherlands, 2019; pp. 380-385.

58. Olariu, S. Smart Communities: From Sensors to Internet of Things and to a Marketplace of Services. In Proceedings of the 9th International Conference on Sensor Networks, Valletta, Malta, 28-29 February 2020; SCITEPRESS-Science and Technology Publications: Valletta, Malta, 2020; pp. 7-18. [CrossRef]

59. Fares, N.; Sherratt, R.S.; Elhajj, I.H. Directing and Orienting ICT Healthcare Solutions to Address the Needs of the Aging Population. Healthcare 2021, 9, 147. [CrossRef]

60. Hu, J. Derivation of trust federation for collaborative business processes. Inf. Syst. Front. 2011, 13, 305-319. [CrossRef]

61. Buxmann, P.; Hess, T.; Ruggaber, R. Internet of Services. Bus. Inf. Syst. Eng. 2009, 1, 341-342. [CrossRef]

62. Sun, Y.; Yan, H.; Lu, C.; Bie, R.; Thomas, P. A holistic approach to visualizing business models for the internet of things. Commun. Mob. Comput. 2012, 1, 4. [CrossRef]

63. Dijkman, R.M.; Sprenkels, B.; Peeters, T.; Janssen, A. Business models for the Internet of Things. Int. J. Inf. Manag. 2015, 35, 672-678. [CrossRef] 
64. Ustundag, A.; Cevikcan, E. Industry 4.0: Managing The Digital Transformation; Springer International Publishing: Cham, Switzerland, 2018. [CrossRef]

65. Chmielewski, J. Device-Independent Architecture for ubiquitous applications. Pers. Ubiquitous Comput. 2014, 18, 481-488. [CrossRef]

66. Frank, A.G.; Mendes, G.H.S.; Ayala, N.F.; Ghezzi, A. Servitization and Industry 4.0 convergence in the digital transformation of product firms: A business model innovation perspective. Technol. Forecast. Soc. Chang. 2019, 141, 341-351. [CrossRef]

67. Gebauer, H.; Paiola, M.; Saccani, N.; Rapaccini, M. Digital servitization: Crossing the perspectives of digitization and servitization. Ind. Mark. Manag. 2021, 93, 382-388. [CrossRef]

68. Smith, M.J. Getting value from artificial intelligence in agriculture. Anim. Prod. Sci. 2020, 60, 46. [CrossRef]

69. Liu, Y.; Han, W.; Zhang, Y.; Li, L.; Wang, J.; Zheng, L. An Internet-of-Things solution for food safety and quality control: A pilot project in China. J. Ind. Inf. Integr. 2016, 3, 1-7. [CrossRef]

70. Tzounis, A.; Katsoulas, N.; Bartzanas, T.; Kittas, C. Internet of Things in agriculture, recent advances and future challenges. Biosyst. Eng. 2017, 164, 31-48. [CrossRef]

71. Lezoche, M.; Hernandez, J.E.; Díaz, M.D.M.E.A.; Panetto, H.; Kacprzyk, J. Agri-food 4.0: A survey of the supply chains and technologies for the future agriculture. Comput. Ind. 2020, 117, 103187. [CrossRef]

72. Matysiewicz, J.; Smyczek, S. Determinants of the Relationship of Medical Service Entities in the Virtual Environment. Sustainability 2020, 12, 7780. [CrossRef]

73. Jiao, R.; Commuri, S.; Panchal, J.; Milisavljevic-Syed, J.; Allen, J.K.; Mistree, F.; Schaefer, D. Design Engineering in the Age of Industry 4.0. J. Mech. Des. 2021, 143, 070801. [CrossRef]

74. Müller, J.; Buliga, O. Archetypes for data-driven business models for manufacturing companies in industry 4.0. In Proceedings of the International Conference on Information Systems (ICIS); Association for Information Systems (AIS), Munich, Germany, 15-18 December 2019. 